\title{
RELATO DE EXPERIÊNCIA DE PRÁTICA PEDAGÓGICA SOB A PERSPECTIVA DA FORMAÇÃO INTERDISCIPLINAR DE PROFESSORES ${ }^{1}$
}

\author{
REPORT OF EXPERIENCE OF PEDAGOGICAL PRACTICE UNDER A \\ PERSPECTIVE OF INTERDISCIPLINARY TEACHER FORMATION
}

\author{
Maryeli Corrêa Cheiram², Mariza Gorette Seeger ${ }^{3}$ e Janaína Pereira Pretto Carlesso ${ }^{4}$
}

\section{RESUMO}

Este trabalho consiste em um relato de experiência, resultante de uma prática pedagógica, aplicada na disciplina Seminário Integrado I, no Mestrado em Ensino de Humanidades e Linguagens da Universidade Franciscana de Santa Maria, RS. Este estudo teve como objetivo unir os conhecimentos da Interdisciplinaridade e Transdisciplinaridade aliados às Técnicas de Ensinagem para o desenvolvimento de uma prática pedagógica sob a perspectiva interdisciplinar na formação de professores e suas utilizações em sala de aula. Constatou-se que o uso de metodologias ativas no processo de ensinagem produziram interação, descontração e alegria ao grupo de participantes. Dessa forma, concluiu-se ser de grande relevância às práticas pedagógicas a utilização de metodologias ativas em sala de aula por facilitar o processo de ensino e aprendizagem, tornando-os mais significativos aos envolvidos.

Palavras-chave: Interdisciplinaridade, Transdisciplinaridade, Prática Pedagógica, Formação de Professores.

\section{ABSTRACT}

This work consists of an experience report, resulting from a pedagogical practice, applied in the discipline Integrated Seminary I, in the Master's degree in Teaching of Humanities and Languages of the Franciscan University of Santa Maria, RS. This study aimed to unite the knowledge of Interdisciplinarity and Transdisciplinary together with teaching techniques for the development of a pedagogical practice from an interdisciplinary perspective in teacher education and their uses in the classroom. It was found that the use of active methodologies in the teaching process produced interaction, deconcentrating and joy to the group of participants. Thus, it was concluded that pedagogical practices were of great importance to use active methodologies in the classroom for facilitating the teaching and learning process, making them more significant to those involved.

Keywords: Interdisciplinarity, transdisciplinary, Pedagogical Practice, Teacher Training.

\footnotetext{
$1 \mathrm{O}$ artigo é resultado da disciplina de Seminário Integrado I do Mestrado em Ensino de Linguagens e Humanidades da UFN. 2 Mestrado em Ensino de Humanidades e Linguagens - Universidade Franciscana. E-mail: marycorreacontato@outlook.com 3 Mestrado em Ensino de Humanidades e Linguagens - Universidade Franciscana. E-mail: mseeger2002@yahoo.com.br 4 Docente dos cursos de Psicologia e Mestrado em Ensino de Humanidades e Linguagens - Universidade Franciscana. E-mail: janaina.carlesso@ufn.edu.br
} 


\title{
INTRODUÇÃO
}

Atualmente, a Educação em seu sentido mais amplo passa por profundas modificações decorridas das intensas transformações científicas e tecnológicas nas sociedades mundiais. Sendo assim, necessitamos nos aproximar do saber de diversos campos do conhecimento, em busca desse elo, surge a proposta interdisciplinar que objetiva romper com as barreiras entre as disciplinas e superar o compartimentalismo do pensar. Desse modo, as práticas pedagógicas no ensino superior devem se embasar na ação e não na intenção de ensinar, pois a educação básica deve ser pensada pela transdisciplinaridade do ensino (KOCHHANN; OMELLI; PINTO, 2006).

Cabe ressaltar aqui a significação dos termos de interdisciplinaridade e transdisciplinaridade para um melhor entendimento sobre esta temática. Assim, nas palavras do mesmo autor:

\begin{abstract}
Fica evidenciado que os educadores precisam analisar a interdisciplinaridade a partir do significado dos seus elementos constitutivos - de sua prática. O termo Interdisciplinaridade se compõe de um prefixo - inter - e de um sufixo - dade - que, ao se justaporem ao substantivo - disciplina - nos levam à seguinte possibilidade interpretativa, onde: inter, prefixo latino, que significa posição a ação intermediária, reciprocidade, interação. Por sua vez, dade (ou idade) sufixo latino, guarda a propriedade de substantivar alguns adjetivos, atribuindo -lhes o sentido de ação ou resultado de ação, qualidade, estado ou, ainda, modo de ser. Já a palavra disciplina, núcleo do termo, significa a epistemé, podendo também ser caracterizado como ordem que convém ao funcionamento duma organização ou ainda um regime de ordem imposta ou livremente consentida (KOCHHANN; OMELLI; PINTO, 2006, p. 3).
\end{abstract}

Na década de 1970, surgem as primeiras discussões acerca da interdisciplinaridade no Brasil. Já, na década de 80, Fazenda (1995) buscou demonstrar a identidade perdida durante as décadas de 1950 a 1970, que ficaram conhecidas por tempo de silêncio. Mais tarde, na década de 1990, oportunizou-se a explicitação de um projeto antropológico de educação, denominado de interdisciplinar, destacando suas principais contradições. Modernamente, podemos dizer que conceitualmente interdisciplinaridade encontra-se diretamente ligado ao conceito de disciplina e sua interpretação da evolução do conhecimento e sua história. Nessa perspectiva Fazenda (2008) destaca:

Assim se tratamos de interdisciplinaridade na Educação, não podemos permanecer apenas na prática empírica, mas é imperioso que se proceda à uma análise detalhada dos porquês dessa prática histórica e culturalmente contextualizados (FAZENDA, 2008, p. 97).

Convém lembrar, ainda, que muitos acadêmicos receberam suas formações a partir do método tradicional, logo, carecem de novos métodos de ensino nos dias atuais. Justifica-se, assim, a importância de estudos com enfoque no ensino de práticas pedagógicas inter e transdisciplinar. Diante desta necessidade, surgiu este relato de experiência, cujo texto tem como objetivo relatar sobre uma prática pedagógica realizada em sala de aula, aliando-se à discussão dos textos "Interdisciplinaridade e Transdisciplinaridade na Formação de Professores" (FAZENDA, 2008) e "Processos de Ensinagem 
na Universidade" (ANASTASIOU; ALVES, 2009), cujos textos forneceram os subsídios necessários ao desenvolvimento da referida atividade.

Essa prática pedagógica foi realizada em sala de aula, tendo sido aplicada na disciplina Seminário Integrado I do Mestrado em Ensino de Humanidades e Linguagens da Universidade Franciscana de Santa Maria, RS. Esta atividade foi proporcionada à turma de mestrandos(as), onde usou-se da primeira estratégia de ensinagem chamada: "Aula expositiva e dialogada" (ANASTASIOU; ALVES, 2009) para fazer introdução do conteúdo e uma dinâmica de grupo, construída pelas autoras.

\section{REFERENCIAL TEÓRICO}

O referencial teórico composto neste relato de experiência foi extraído dos textos "Interdisciplinaridade e Transdisciplinaridade na Formação de Professores" e "Processos de Ensinagem na Universidade", que serviram também à construção da prática pedagógica. Nas seções seguintes, abordaremos, de forma sucinta, algumas considerações sobre a temática de cada texto.

\section{INTERDISCIPLINARIDADE NA FORMAÇÃO DE PROFESSORES}

Sob a perspectiva da Interdisciplinaridade, Fazenda (2008), cita FOUREZ (2001) para discuti-la, este autor divide em duas ordens distintas a interdisciplinaridade na formação de professores. São elas: ordenação científica e ordenação social. Na fase em que ocorre a ordenação científica, em cujo momento a organização dos saberes serve como alicerce do conhecimento científico no ato de formar professores; ocorre, ainda, nesta fase, a análise de saberes interdisciplinares (conceitos enunciados e em seus movimentos de cientificidade), e, por fim, neste período científico o professor é obrigado a rever suas práticas e a redescobrir seus talentos ao incorporar o movimento da disciplina ao seu; Com essa mesma visão, Lenoir (2001), diz que o saber se legitima pela abstração - um saber/ saber nesta ordenação.

A outra fase citada por Fazenda (2008), denomina-se de ordenação social, momento em que ocorre o desdobramento dos saberes científicos interdisciplinares às exigências sociais, políticas e econômicas; onde se capta o real e a necessidade de levar em conta suas interações; ocorrem, ainda, neste processo o estudo dos métodos de análise do mundo por suas finalidades sociais, enfatizando a complexidade das disciplinas científicas; além disso, aqui, leva-se em conta o sentido da prática, do "para que serve", impõe-se como forma de inserção cultural essencial e básica - "saber fazer".

Quanto a $3^{\mathrm{a}}$ ordenação, segundo Fazenda (2008), entende-se por “saber ser", forma brasileira de formar professores, nesta fase, ocorre intenso interesse pelas análises de pesquisas sobre Interdisciplinaridade na formação de professores no Brasil; ocorre, também, a inclusão da experiência 
docente em seu sentido, intencionalidade e funcionalidade, diferenciando o contexto científico do profissional e do prático (LENOIR, FAZENDA, 2001); neste processo, surgem, ainda, os cuidados às pré-suposições teóricas para verificar a formação do professor, relacionar os saberes ao tempo e espaço vividos por ele, investigando, também, os conceitos que movem as suas ações e, por fim, constatar se existe coerência entre o que ele diz e faz.

Entendendo-se aqui, que as três ordens constituem o processo interdisciplinar durante a formação de professores. A primeira, ordenação científica, como já diz, ordena de forma científica trazendo os conceitos, estruturas e demais elementos científicos se que pode encontrar neste processo (saber científico, grifo meu!).

Já a segunda, ordenação social, conforme já citado, leva em consideração outros elementos, como, social, econômico e político da temática trabalhada. É preciso ir muito além da simples conceituação dos termos, é preciso interagir com a temática, analisar seu contexto histórico etc (saber prático, grifo nosso!). E, finalmente, a terceira, ordenação do "saber ser", cuja fase entra um novo elemento, a experiência docente como parte deste processo interdisciplinar.

\section{Transdisciplinaridade na Formação de professores}

Para Fazenda (2008), os termos de Interdisciplinaridade e Transdisciplinaridade no mencionado texto não foram tratados como diferentes, mas como auto inclusos e, ainda, como complementos deste processo. Desse modo, as questões que envolvem Inter e Transdisciplinaridade não se diferenciam, elas se incluem e complementam-se, pois não podemos analisar uma sem averiguar a outra. Ambas estão entrelaçadas, devemos tentar verificar os limites de cada uma haja vista a transdisciplinaridade ter uma amplitude maior de que a interdisciplinaridade.

Além disso, a autora menciona em seu texto que questões como: a necessidade do diálogo, a adoção de um olhar transdisciplinar, questões relativas a complexidade, autoformação, eco-formação e, heteroformação ganham destaque cada vez maior entre os estudiosos da Transdisciplinaridade.

Outras questões merecem destaque acerca do processo de Formação de professores, são diferentes olhares para esta tão complexa área. A demanda diversa da Educação fez surgir novos estudos sobre variadas formas de pensar a formação de docentes, logo a Transdisciplinaridade passou a fazer parte dessas emergentes pesquisas. Para Fazenda (2008), há alguns princípios a serem observados ao abordar as questões de inter e transdisciplinaridade no processo interdisciplinar de Formação de professores. Em suas palavras:

Em várias de minhas obras recorro a princípios que sintetizo em palavras como: Espera, Coerência, Humildade, Respeito e Desapego, sob a estreita vigilancia de um Olhar multifacetado e atento, síntese essa que tomo como necessária ao pensar Inter ou Transdisciplinaridade nas pesquisas que oriento e realizo (FAZENDA, 2008, p. 101). 
Nesse sentido, "Espera, Coerência, Humildade, Respeito e Desapego" são princípios norteadores de novas pesquisas e estudos relacionados às questões de Inter e Transdisciplinaridade, onde o pesquisador deve levar em conta outros sentimentos envolvidos nessas metodologias, as quais servem de norte ao processo de Formação de professores. Em suas reflexões finais, a mesma autora aponta para a relevância do território transdisciplinar, cujos estudos interdisciplinares não podem prescindi-los. Em síntese:

O cuidado construído arduamente nos dois territórios precisa ser devidamente respeitado em suas limitações, mas principalmente nas inúmeras possibilidades que se abrem para uma educação diferenciada onde o caráter humano se evidencia (FAZENDA, 2008, p. 102).

A Transdisciplinaridade é entendida aqui como a metodologia que ultrapassa os limites da Interdisciplinaridade, ou seja, como se as disciplinas relacionadas se fundissem em uma outra disciplina ("macrodisciplina"). De onde se pudesse ter uma visão bem mais ampla sobre as temáticas analisadas, ir além do interdisciplinar, pudesse, assim, conforme a citada autora, evidenciar o caráter humano no processo formativo docente.

\section{PROCESSOS DE ENSINAGEM NA UNIVERSIDADE}

O processo de Ensinagem na Universidade, citados por Anastasiou e Alves (2009), são desenvolvidos em estratégias de trabalho docente, e estão divididos em 19 estratégias. Neste trabalho, em primeiro momento, utilizou-se da estratégia 1: Aula expositiva dialogada, onde o texto foi exposto e os alunos puderam dividir suas experiências, suas dúvidas e também deram suas contribuições acerca do texto discutido.

A utilização desta estratégia deu-se por conta da referida autora acreditar que não se pode mais ensinar como no século passado, os alunos tem novos anseios, que estão em constantes mudanças, por isso ela sugere novas metodologias para ensinar e aprender abordando essa perspectiva interdisciplinar. "É nesse contexto que se constrói o trabalho docente e que o professor se vê a frente a frente com a necessidade e o desafio de organiza-lo e operacionaliza-lo" (ANASTASIOU; ALVES, 2009, p. 68).

Sendo assim, foi pensando nessa necessidade de enfrentar os desafios é que a dinâmica foi introduzida em segundo momento. Ainda para mesma autora o processo de trabalho em dupla são um desafio reconhecido e enfrentado, além de considerar que a dinâmica exige planejamento e engajamento do professor para com o aluno (ANASTASIOU; ALVES 2009).

Em consideração a esse relevante processo de ensinagem, na seção seguinte serão apresentados os procedimentos metodológicos que nortearam a prática pedagógica desenvolvida em sala de aula, os quais foram baseados em tais pressupostos. 


\section{METODOLOGIA}

O relato de experiência é resultado do uso de metodologias ativas em sala de aula, sendo realizada em dois momentos, apresentados a seguir.

$1^{0}$ ) Primeiro momento: Aula expositiva e dialogada (ANASTASIOU; ALVES, 2009), abordando os principais tópicos do texto.

Para Fazenda (1995), a questão da Interdisciplinaridade consiste em: "É tentar formar alguém a partir de tudo o que você já estudou em sua vida". "Dar visibilidade ao talento e movimento escondido que existe em cada um de nós”. O objetivo dessa metodologia, é muito mais profundo do que procurar interconexões entre as diversas disciplinas, alicerça-se no diálogo e colaboração, no desejo de criar e pesquisar, possibilitando transformar a realidade mundana e histórica numa aquisição maior de educação, humanizante e libertadora do ser no mundo (FAZENDA, 1995). A partir dos tópicos acima, foi introduzido o assunto acerca da Interdisciplinaridade para a turma de mestrandos. Além disso, restou interessante, na referida exposição, distinguir os conceitos de multidisciplinaridade, interdisciplinaridade e transdisciplinaridade, que podem ser entendidos como:

\footnotetext{
Na multidisciplinaridade, recorremos a informações de várias matérias para estudar um determinado elemento, sem a preocupação de interligar as disciplinas entre si.

$\mathrm{Na}$ interdisciplinaridade, estabelecemos uma interação entre duas ou mais disciplinas;

Na transdisciplinaridade, a cooperação entre as várias matérias é tanta, que não dá mais para separá-las: acaba surgindo uma nova "macrodisciplina". (GIRARDELLI, 2007)
}

Observando, ainda, que outros dois tópicos foram expostos pelas ministrantes: Formação interdisciplinar de professores (FAZENDA, 2008) e Transdisciplinaridade na Formação de professores (FAZENDA, 2008). Para concluir o primeiro momento, foram expostas as considerações finais sobre a temática de ambos os textos.

\section{$2^{\circ}$ ) Segundo momento: Dinâmica "Enfrentando desafios" (perguntas e desafios)}

\section{Objetivo(s) da dinâmica:}

- Observar o quanto as pessoas têm receio de enfrentar desafios, pois elas terão pressa de passar a caixa para o outro participante;

- Demonstrar que os desafios aparecem de diversas formas, depende de cada situação apresentada, assim, a caixa traz três tipos desafios: perguntas com assertiva correta, nada recebe, apenas 
amplia o conhecimento do participante; já a resposta errada recebe o desafio prescrito no envelope; e, por fim, uma possibilidade de desafio agradável, no caso, de abrir o envelope com bombom.

- Mostrar aos participantes que embora os desafios nos causem desconforto e insegurança, muitas vezes, são molas propulsoras para que enfrentemos outras situações com mais facilidade.

\section{Procedimentos à aplicação da dinâmica}

Iniciar a dinâmica abordando a questão dos desafios e como são percebidos na vida profissional e pessoal. Averiguar se os participantes do grupo se consideram preparados para enfrentar novos desafios ou se isso lhes causa muita ansiedade para eles. Na sequência, solicitar ao grupo para narrar objetivamente os desafios mais difíceis pelos quais já passaram na jornada profissional.

Logo em seguida, apresentar a caixa aos participantes e lhes informar de que há dentro dela alguns desafios surpresas que devem ser realizados a cada vez que a música parar. Nos passos seguintes, colocar uma música animada para tocar, uma pessoa de costas para desligar a música quando desejar, logo começar a passar a caixa de mão em mão no círculo montado com os participantes do grupo.

Enquanto a caixa estiver passando de mão em mão, observe o comportamento dos participantes. Suas reações podem variar entre os mais ansiosos em passar o embrulho, ou os que apresentam maior tranquilidade, ou ainda, os mais aflitos e ansiosos para pegar logo o pacote e se livrarem dele.

Quando a música parar, o organizador fará um pequeno suspense e dará a opção de quem pegou a caixa passá-la para frente. Ele pode fazer perguntas como:

\footnotetext{
- Nossa, então você foi o sortudo? Você tem a opção de passá-la para o colega da frente, você gostaria?;

- Está preparado?; ou

- Você vai ter que pagar o mico, viu?; [e ainda]

- Chegou a hora de você ser desafiado, você vai saber lidar com isso?
}

Fazer isso até que alguém decida abrir a caixa. Lá dentro haverá três diferentes formas de desafios: três envelopes com perguntas de múltipla escolha, caso erre, enfrenta o desafio; caso acerte, nada recebe, apenas amplia seu conhecimento a respeito da temática; e em mais três envelopes, tem um desafio surpresa que é um delicioso bombom. A intuito desta é demonstrar que ao encararmos os desafios, podemos ter variadas surpresas que podem ser agradáveis ou difíceis de realizar, vai depender de cada situação.

Quando o desafio for revelado, perceba a reação da pessoa desafiada. Verifique a sua surpresa, seu semblante, a comunicação corporal dela, os comentários que fizer com os colegas. Perceba também a reação do restante do grupo. Veja se alguns se sentiram desapontados ou aliviados pela caixa não ter caído em suas mãos. 
Dê um espaço para que cada um comente a dinâmica apresentada. Nesse momento, é possível prosseguir com os comentários feitos antes da dinâmica com mais detalhamento. Deixe que os presentes falem sobre os desafios positivos com os quais já lidaram ao longo da vida profissional e como isso foi gratificante e compensador.

Na sequência, segue a figura com as perguntas de múltipla escolha e o desafio surpresa que foram colocados em envelopes brancos e acomodados na caixa surpresa.

Figura 1 - Passos da dinâmica ${ }^{5}$

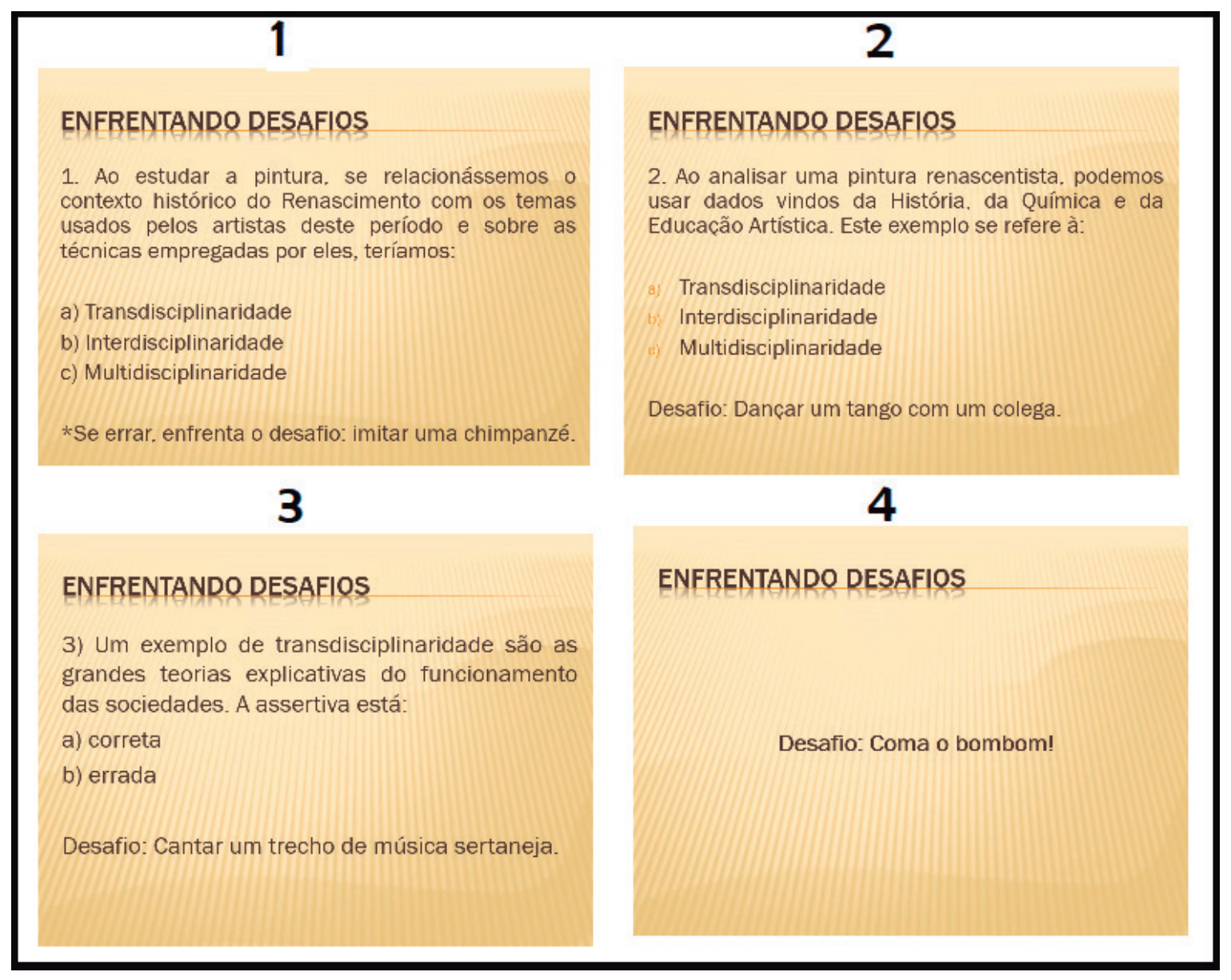

Fonte: Elaborado pelas pesquisadoras.

\section{Análise da prática}

O mais importante na realização de uma prática, é a análise dela. Não basta por si faze-la, se não ocorrer uma análise do que foi realizado. Essa análise de toda e qualquer prática realizada em sala de aula, possibilita um olhar crítico sobre a mesma, proporcionando melhora e ajustes que podem contribuir para que a prática possa ser aplicada outras vezes e até mesmo por outros professores e educandos.

\section{Gabarito das questões:}

$1^{\mathrm{a}}$ questão - assertiva correta b) Interdisciplinaridade.

$2^{\mathrm{a}}$ questão - assertiva correta b) Multidisciplinaridade.

$3^{a}$ questão - assertiva correta b) Transdisciplinaridade. 
Assim, essa atividade terá como análise, a análise através da observação e de reflexões subjetivas. Observar é fundamental, para que se possa compreender e analisar os sujeitos, em suas relações, que podem ocorrer entre si, e com o meio em que se relacionam (SILVA; ARAGÃO, 2012). Ao observar é possível chegar a uma percepção mais profunda acerca das práticas. Ainda afirmam os autores, que observar é uma ferramenta que se torna fundamental para processo de descoberta e de compreensão do mundo (SILVA; ARAGÃO, 2012).

A observação não é uma forma de análise sem objetivos, mas sim uma forma crítica de perceber a realidade. Nesse sentido os objetivos são: Verificar se os participantes apresentam empenho durante a realização da mesma; se há motivação; se sentem desafiados pela prática. Para isso observou-se o grupo e cada indivíduo participante da dinâmica e nessa análise, levou-se em conta, os sentimentos que os mesmos expressaram através da leitura corporal e da forma como se comportaram diante da prática.

\section{RESULTADOS E DISCUSSÃO}

A formação docente é feita através da observação, observação essa, que contempla todos os elementos de uma sala de aula. Percebendo as dificuldades, para que possa se preparar para os novos desafios que consiste em ensinar. Observar é um ato de conhecer melhor a situação e encontrar alternativas para resolvê-la.

Segundo Piconez (1991), refletir sobre uma prática vivenciada, que tenha sido pensada teoricamente, é construir uma postura crítica sobre ela, possibilitando que haja uma percepção sobre possíveis problemas ou fragilidades da prática. Assim torna-se possível perceber o quanto é importante analisar as práticas vivenciadas. Nesse sentindo também, ressalta-se que como trata-se se de uma atividade com dois momentos, onde há uma relação entre a teoria e a prática, é sempre válido analisar como elas se entrelaçam.

Seguindo os objetivos destacados anteriormente na metodologia, sobre a reflexão da prática, como: empenho na realização da dinâmica, motivação e desafio, foram feitas algumas análises e observações subjetivas. Observou-se que, nos momentos de aplicação da dinâmica, houve intensa interação, desconcentração e alegria por parte dos participantes na realização das atividades propostas pelas autoras. Momentos marcados pelos movimentos de "saber, fazer e ser" dos envolvidos, demonstrando a importância de constante atualização na formação interdisciplinar desses professores.

Segundo Freire (1992), olhar para uma prática pedagógica consiste em admirá-la, olha-la, envolve-se acordado para a realidade dela. Nesse sentido pode-se perceber a partir dos gestos, leitura corporal e comentários, que há uma grande motivação na realização da prática. Quando se fala que vai ocorrer uma atividade prática de dinâmica, com surpresa, todos os participantes se propõem rapidamente a levantar-se das classes, formar um círculo, onde nota-se uma empolgação. Os participantes apresentaram semblantes de felicidade. 
Inicialmente, os presentes deveriam narrar sobre seus desafios positivos ou negativos com os quais já lidaram ao longo da vida profissional, demonstraram bastante segurança para enfrentá-los em suas narrativas e que, de forma ou outra, tornaram-se gratificantes e compensadores às suas expectativas e experiências. É muito importante que se tenha uma escuta na formação docente, pois assim há uma troca de experiências, onde se torna possível um aprendizado a partir do desafio que o outro já enfrentou, o que enriquece a prática. Pois aprende-se muito com as experiências vivenciadas pelos outros sujeitos.

Na sequência, verificou-se que alguns dos participantes se sentiram desapontados ou aliviados pela caixa não ter caído em suas mãos, no entanto todos entraram na brincadeira e participaram ativamente. A música nesse momento faz com que os participantes se sintam envolvidos e descontraídos. Enquanto a caixa passa e a música toca, os participantes mexem-se, conversam uns com os outros, trocam sorrisos e demonstram estar motivados a resolver os possíveis desafios. Segundo Moreira, Santos e Coelho (2014, p. 41), “(...) a música permeia o desenvolvimento cognitivo, afetivo e expressivo (...)". O que faz com que a música se torne um importante recurso para a sala de aula, já que a mesma pode mudar o ambiente.

Sobre a música e práticas pedagógicas, afirmam os autores:

\begin{abstract}
Sabendo que há escolas e professores que preparam aulas que não despertam o interesse dos alunos, ocasionando a falta de atenção, o baixo rendimento escolar e um aprendizado mecânico, pretendemos identificar na literatura existente, como a música pode ser um recurso didático e o porquê a mesma não é utilizada com mais frequência como recurso de aprendizagem e memorização dos assuntos de cada disciplina, proporcionando assim uma aula mais dinâmica (MOREIRA; SANTOS: COELHO, 2014, p. 42).
\end{abstract}

Assim, a prática também motiva que os participantes possam utilizar mais de recursos diferentes para as suas práticas em sala de aula, como a música, que traz consigo uma diversão, dinâmicas, brincadeiras e etc, pois nos dias atuais, se faz necessário, incorporar práticas que chamem a atenção, que estimulem interesse para que assim, o aprendizado possa ser de fato efetivado. Aprendizado esse, que neste caso, deve ocorrer de forma ativa pelo aluno, e não mecânica, como cita as autoras no parágrafo acima.

Ao se depararem com as questões contidas nos envelopes, percebeu-se que os participantes se sentiram bastantes desafiados uma vez que as perguntas eram bem complexas. Além disso, somava-se o fato de que se errassem o questionamento, seriam desafiados novamente, sendo que deveriam pagar uma prenda, prevista no envelope. Foram momentos de descontração, mas também de tensão por parte dos participantes, que queriam acertar as perguntas, para não correr o risco de pagar a prenda, despertando muita curiosidade até o final da brincadeira.

Acredita-se, ainda, que por meio desta prática, os professores foram estimulados a refletir e tomar novas atitudes referentes à renovação de suas práticas pedagógicas, uma vez que ficou demonstrado que se aprende de forma mais significativa com o lúdico, que obstáculos mesmo desafiadores são superados e, muitas das vezes, eles nos surpreendem por nos trazerem resultados positivos. 


\section{CONSIDERAÇÕES FINAIS}

Considerou-se que o uso de metodologias ativas em sala de aula é muito importante. Nos momentos que ocorreram a dinâmica, os próprios participantes consideraram que práticas interativas são mais válidas para facilitar o processo de ensino e aprendizagem. Nos dias atuais é fundamental que as aulas sejam interessantes, que despertem a atenção dos alunos, que possibilitem que os mesmos se sintam motivados a tornarem-se ativos no seu processo de ensino e que os envolvam ao conteúdo. Pensar em aulas divertidas, que tenham proposito e objetivos pedagógicos bem definidos para proporcionar o aprendizado dos educandos. Nesse sentido o ensino é pensado e destinado aos educandos.

A busca por proporcionar atividades que chamem mais a atenção dos educandos, é essencial. A prática em questão chamou a atenção dos participantes, por ser uma atividade diferente das convencionais realizadas em sala de aula, o que proporcionou, que os mesmos fossem envolvidos na atividade. Considera-se, assim pelas observações subjetivas durante a aula que a dinâmica, foi executada com objetivos atrelados ao conteúdo, unindo teoria e prática, sendo válida a sua aplicação e servindo como sugestão para a aplicação desta em outros momentos e até com outras temáticas.

A importância do relato de experiência é deixar um registro para que outros professores e educandos possam usa-las e até inspira-las para a criação de novas práticas. Também pode ser utilizada como uma forma reflexiva acerca de suas próprias praticas em sala de aula. Constatou-se, ainda, que a Interdisciplinaridade não envolve apenas trabalhar disciplinas juntas, mas também aproximar o ensino do cotidiano dos educandos uma vez que se objetiva fazer um processo de ensino mais significativo ao aluno. Possibilitando que o mesmo se sinta envolvido e motivado pelas práticas, protagonista do seu processo de ensino.

Assim, pode-se fazer uso da interdisciplinaridade como temática desta aula, refletindo sobre ela e possibilitando uma discussão crítica dos textos e um aprendizado por meio de desafios. Desta forma, a utilização das metodologias ativas, e recursos pedagógicos como suas aliadas em sala de aula, consequentemente, podem enriquecer suas práticas pedagógicas, tornando seu "saber, fazer e ser" como partes integrantes do processo de ensino-aprendizagem dos educandos.

\section{REFERÊNCIAS}

ANAStASIOU, L. D. G. C. AlVES, L. P. (Orgs.). Processos de ensinagem na universidade: pressupostos para as estratégias de trabalho em aula. Joinville, SC: UNIVILLE, 2009.

FAZENDA, I. C. A. Interdisciplinaridade: história, teoria e pesquisa. 2. ed. Campinas, SP: Papirus, 1995. 
FAZENDA, I. C. A. Interdisciplinaridade e Transdisciplinaridade na formação de Professores. Ideação - Revista do Centro de Educação e Letras da Unioeste - Campus de Foz do Iguaçu, v. 10 n. 1, p. 2008.

FAZENDA, I. C. A. Práticas interdisciplinares na Escola. São Paulo: Cortez, 2001.

FOUREZ, G. Fondements épistémologiques pour l'interdisciplinarité. In (Org.) LENOIR, REY, B. FAZENDA, I. Les fondements de l'interdisciplinarité dans la formation à l'enseignement. Sherbrooke: Éditions du CRP, 2001

FREIRE, M. Observação, Registro, Reflexão: Instrumento Metodológico. Série Seminários. São Paulo: Espaço Pedagógico, 1992.

GIRARDELLI, M. de F. Qual é a diferença entre multidisciplinaridade, interdisciplinaridade e transdisciplinaridade? Manaus, AM. Disponível em: https://bit.ly/3tZAL4C. Acesso em: 20 de jun. de 2018 .

KOCHHANN, A.; OMELli, C.; PINTO, U. A. A Prática Interdisciplinar na Formação de Professor: Uma Necessidade Paradigmática. Colóquio da UFG (Universidade Federal de Goiás), no Encontro da UEG (Universidade Estadual de Goiás) Unidade das Laranjeiras em 2006 e atualizado em março de 2007.

LENOIR, Y. L. Interdiscplinaire dans la formation à l'enseignement: des lectures distinctes en fonction de cultures distinctes. In (Org.) LENOIR, Y, REY, B. FAZENDA, I. Les fondements de l'interdisciplinarité dans la formation à l'enseignement. Sherbrooke: Éditions du CRP, 2001.

MOREIRA, A. C.; SANTOS, H.; COELHO, S. I. A música na sala de aula - a música como recurso didático. UNISANTA - Humanitas. v. 3, n. 1, 2014. Disponível em: https://bit.ly/2W03nOq. Acesso em: 24 de Ago. 2021.

PICONEZ, S. C. B. (org). A Prática de Ensino e o Estágio Supervisionado. Campinas/SP: Editora Papirus, 1991.

SILVA, N. M. da.; ARAGÃO, R. F. A Observação como Prática Pedagógica no Ensino de Geografia. Fortaleza: Geosaberes, 2012. 